\title{
Erratum to: Furongian conodonts from the Machari Formation in the Gokgeum section, Yeongwol, Korea
}

\author{
Byung-Su Lee* Department of Earth Science Education, Chonbuk National University, Jeonju 561-756, Republic of Korea
}

Erratum to: Geosciences Journal, 2012, 16, 17-23

DOI 10.1007/s12303-012-0006-7

The original version of the article contained some errors in citation. The corrected citations are supplied here.

1. In the references list, the reference below is substituted with new one as follows.

Roh, D.Y., 2011, Depositional environment of the Machari Formation in the Yeongweol area, Kangweon-do, Korea. Ms Thesis (unpublished).

$\rightarrow$ Noh, D.Y., 2009, Stratigraphic Interpretation of the Middle to Upper Cambrian Machari Formation in Seo-Myeon, Yeongwol, Kangwon, Korea. B.Sc. thesis, Chungbuk National University, Cheongju, 43 p. (in Korean)

2. The caption of figure 1 is changed into as follows.

Fig. 1. Geologic map showing the location of the Gokgeum section of the Machari Formation in the Yeongweol area, Korea (modified from Noh, 2009).

3. The caption of figure 2 is changed into as follows.

Fig. 2. Lithology and sample horizons of the Gokgeum section. Key for lithology: $L-s a$, limestone-shale alternation; Lms, shale-parted lime mudstone; $L m l$, laminated lime mudstone; $B l$, lime breccia; $L m b$, bioturbated lime mudstone; Lmt, thin-bedded lime mudstone; Dm, massive dolostone; $\mathrm{Lm}$, lime mudstone (logging and facies data followed Noh, 2009).

The online version of the original article can be found under DOI 10.1007/s12303-012-0006-7

*Corresponding author: bslee@chonbuk.ac.kr 